\title{
Self-Esteem and Academic Stress among Nursing Students
}

\section{Acharya Pandey $\mathrm{R}^{1}$ Chalise $\mathrm{HN}^{2}$}

\author{
${ }^{1}$ Department of Nursing \\ Kathmandu University School of Medical Sciences \\ Dhulikhel, Kavre, Nepal. \\ ${ }^{2}$ School of Arts \\ Kathmandu University \\ Hattiban, lalitpur, Nepal.

\section{Corresponding Author} \\ Radha Acharya Pandey \\ Department of Nursing \\ Kathmandu University School of Medical Sciences \\ Dhulikhel, Kavre, Nepal. \\ E-mail: radhapnd@yahoo.com
}

Citation

Acharya Pandey R. Chalise HN. Self-Esteem and Academic Stress among Nursing Students. Kathmandu Univ Med J 2015;52(4):298-302.

\section{ABSTRACT}

\section{Background}

Stress and self-esteem are common issues that everyone has to cope with at some time in their lives and they could also affect other things going on in a persons' life. Academic stress is psychological condition often experienced by college students as, to some extent, being multidimensional variables. Among others are self-esteem and psychological well-being which are considered to have influences in explaining why college students experience stress.

\section{Objective}

The objective of this study was to assess the self-esteem level and academic stress among the nursing students.

\section{Method}

This is a cross-sectional study carried out in 2012. Total respondents were 190 nursing students selected randomly from Kathmandu University. Academic stress was assed using 30-item Scale for Assessing Academic Stress (SAAS) and Self esteem was assessed using 10 item Rosenberg's Self-Esteem Scale. Information was collected through the self-administered questionnaire. The collected data was analyzed using SPSS version 16 software. Simple statistics measurement, percentage, means, correlation was used for the data analysis.

\section{Result}

This study shows mean age of the respondent's was $20.44 \pm 2.67$ years. Majority $(88 \%)$ of students getting financial support of less than NRs 6000 per month and $64 \%$ have low perceived family support. This study found mean score of self esteem and academic stress was 11.9 and 18.4 respectively. Further nearly $78 \%$ students have low self esteem and $74 \%$ have high academic stress. Significant variable for high academic stress and low self esteem were lower the age, lower the education and low perceived family support. Lower financial support has also high academic stress.

\section{Conclusion}

Nursing students have low self esteem and high academic stress. Intervention to lower the academic stress and increase the self esteem should be carried out so that the learning of students will be efficient.

\section{KEY WORDS}

Academic stress, nursing students, self-esteem 


\section{INTRODUCTION}

Academic stress among college students has been a topic of interest for many years. Stress is defined as a mental or physical tension or strain. ${ }^{1}$ Self-esteem is an important personality trait for healthcare professionals including nursing. ${ }^{2}$ Self-esteem is overall evaluation of one's worth or value and an important predictor of stress coping. Higher stress levels may result in reduction of self-esteem. High self-esteem results in more active and effective coping. ${ }^{3}$

The students' pre existing level of self esteem strongly contributes to successful or maladaptive adjustment to problem. Student with high self esteem shows self confidence and positive expectations in new situations. A new learning environment may be seen as just another challenge and the student will actively participate in learning new behavior. In contrast, a person with low self esteem consistently demonstrates negative feelings about one self and is pessimistic in new situations. ${ }^{4}$

Erikson identified self-esteem as a function of identity development that results from successfully addressing the tasks associated with each of the developmental stages of life. According to him one's sense of developing, growing and confronting lives tasks leads to feelings of worth. ${ }^{5}$ Some researchers showed that self-esteem remains stable or increases by increasing of individual's age, and some researcher discuss that self-esteem decreases, and some of the authors reveal that there is a U-shaped relationship between age and self-esteem. ${ }^{6}$

On the other hand stress is a common phenomenon experienced by every person and has been more and more complex in modern time due to rapid development of technology resulting in the continuous high expectation in the life of the individuals. ${ }^{7}$ Different groups of populations and professionals use different strategies to cope with the stressed experienced. If the stress is not properly coped, it may lead to the initiation of frustrations resulting in to the nervous breakdown/mental ill heath etc. Study shows early stress management can help control these illness as well as help individual improve self esteem, gain control over their lives and enjoy life more fully. ${ }^{7}$

Producing healthy nursing personnel is a part of human resource planning. But, many factors may be the causes of academic stress and that lead to low self esteem of students during the study period. The purpose of this study is to assess self esteem level and academic stress among nursing students and also factor correlated with academic stress and self esteem.

\section{METHODS}

This is a cross-sectional study carried out in 2012 in Kathmandu University, School of Medical Sciences. Total number of students enrolled in the school of medical sciences was 300 . For the purpose of this study 190 students were selected randomly from all three groups of students Proficiency Certificate Level (PCL), Bachelor in Science in Nursing (B.Sc.) and Bachelor in Nursing Science (BNS) nursing students. For the data collection self administered questionnaire was used.

Academic stress was measured using Scale for Assessing Academic Stress (SAAS). ${ }^{8}$ It consisted of 30 -items. This scale has already used and validated in Nepal. ${ }^{8}$ Reliability consistency of this scale measured through alpha reliability was 0.70 in this study showing the satisfactory. The subject has to select one out of two alternative responses (yes and no) for each item of the scale. All yes responses are given one point each and summed-up to get total stress score. In this study academic stress was categorized as low stress (15 and below) and high stress (16 and above).

Self-esteem was assessed with the 10-item Rosenberg Self-Esteem Scale (RSE). ${ }^{9}$ The RSE is the most commonly used and well-validated measure of global self-esteem. Responses were measured on a 5-point scale ranging from one (not very true of me) to five (very true of me). ${ }^{10}$ Which is later changed to 3-point scale ranging from one (not very true of me) to three (very true of me). Scoring was accomplished by summing responses to the questions and mean score. Higher mean score indicates high level of self esteem. The alpha reliability of the RSE was 0.75 in this study. In this study respondents who obtained below 15 score were considered low self esteem level and those who were obtained more than 16 have were considered as high self esteem.

Ethical approval for this study was taken from Kathmandu University School of Medical Sciences, Institutional Review Committee (IRC) Dhulikhel. Purpose of the study was explained to the participants and an informed verbal consent was obtained from all the participants before filling the questionnaire.

In this study educational back ground is classified as Bachelor and Certificate level, type of family is classified as nuclear and joint family, perceived family support is measured by putting as weak and strong option directly based on their perception. Residency of respondents was taken as hostel and out of hostel. Financial support was measured by amount of money received from family members per month and dichotomized as less than NRs 6000 or more than it.

The questionnaire was pretested among nursing students of other nearby college. The questionnaire was distributed using lottery method to the students in the classroom and returned back in the presence of researcher. There was no problem of drop out and incomplete response. Data entry and analysis was carried using SPSS version 16. Percentage, mean, and correlation statistics are used for data analysis. 


\section{RESULTS}

More detail information about the demographic information of the participants are shown in table 1.

Table 1. Demographic information of the respondents $\quad n=190$

\begin{tabular}{|c|c|c|}
\hline Variables & Number & $\%$ \\
\hline \multicolumn{3}{|l|}{ Educational Level } \\
\hline Proficiency Certificate Level (PCL) & 53 & 27.9 \\
\hline Bachelor of Nursing & 137 & 72.1 \\
\hline \multicolumn{3}{|l|}{ Age } \\
\hline $16-18$ & 46 & 24.3 \\
\hline $19-21$ & 73 & 38.4 \\
\hline $22-24$ & 58 & 30.5 \\
\hline $25-27$ & 13 & 6.8 \\
\hline Mean age & $20.44 \pm 2.67$ & \\
\hline \multicolumn{3}{|l|}{ Ethnicity } \\
\hline Brahmin/Chhetri & 97 & 51.1 \\
\hline Newar & 63 & 33.1 \\
\hline Janajati & 30 & 15.8 \\
\hline \multicolumn{3}{|l|}{ Religion } \\
\hline Hindu & 164 & 86.3 \\
\hline Other than Hindu & 26 & 13.7 \\
\hline \multicolumn{3}{|l|}{ Type of Family } \\
\hline Nuclear & 146 & 76.8 \\
\hline Joint & 44 & 23.2 \\
\hline \multicolumn{3}{|l|}{ Marital Status } \\
\hline Unmarried & 182 & 95.8 \\
\hline Married & 8 & 4.2 \\
\hline \multicolumn{3}{|l|}{ Residency } \\
\hline Hostel & 121 & 63.7 \\
\hline Out of Hostel & 69 & 36.3 \\
\hline \multicolumn{3}{|l|}{ Financial Support } \\
\hline$<$ Rs. 6000 & 168 & 88.4 \\
\hline$\geq$ Rs. 6000 & 22 & 11.6 \\
\hline \multicolumn{3}{|l|}{ Perceived Family Support } \\
\hline Weak & 122 & 64.2 \\
\hline Strong & 68 & 35.8 \\
\hline
\end{tabular}

\section{Self Esteem and Academic Stress of the respondents}

Table 2 summarizes the self esteem and academic stress of respondents. Mean score of self esteem and academic stress was $11.9 \pm 6.0$ and $17.4 \pm 4.1$ respectively. Cut off point for low and high self esteem as well as low academic stress and high academic stress was taken as 15 arbitrarily, which is the midpoint of the theoretically possible score range (030). Based on this point, $78 \%$ participants have low self esteem and $74 \%$ participants have high academic stress. Pearson correlation between self esteem and academic stress was -0.58 and which was statistically significant. It shows there is strong negative correlation between self esteem and academic stress in this study.
Table 2. Self esteem and academic stress of the respondents $n=190$

\begin{tabular}{|lll|}
\hline Variable & Self Esteem & Academic Stress \\
\hline Mean (SD) & $11.9 \pm 6.0$ & $18.4 \pm 4.1$ \\
\hline Minimum Score & 4.0 & 1.0 \\
\hline Maximum Score & 27.0 & 28.0 \\
\hline Cut off point for low/High & 15.0 & 15.0 \\
\hline High & $22.1 \%$ & $74.2 \%$ \\
\hline Low & $77.9 \%$ & $25.8 \%$ \\
\hline $\begin{array}{l}\text { Correlation between self esteem } \\
\text { and academic stress }\end{array}$ & $-0.58 *$ & \\
\hline *is significant at the 0.01 level & & \\
\hline
\end{tabular}

\section{Association between study variables with self esteem and academic stress}

Table 3 shows the correlation of demographic variables with self esteem and academic stress. Significant correlation was found between educational level, age and perceived family support.

Higher the academic level higher the self esteem, higher the age higher the self esteem and perceived family support has high self esteem. On the other hand, lower the age, lower the education and less perceived family support is related high academic stress. Further, lower the financial support has higher the academic stress.

Table 3. Association between demographic variables with self esteem and academic stress

$n=190$

\begin{tabular}{lll} 
Variables & Self Esteem & Academic Stress \\
\hline Educational Level & $0.148^{*}$ & $-0.161^{*}$ \\
\hline Age & $0.135^{*}$ & $-0.131^{*}$ \\
\hline Religion & 0.009 & 0.078 \\
\hline Residency & 0.089 & 0.100 \\
\hline Financial Support & 0.002 & $-0.137^{*}$ \\
\hline Perceive Family support & $0.191^{* *}$ & $-0.199^{* *}$ \\
\hline Family type & -0.101 & 0.099 \\
\hline *Pearson's Correlation is significant at the 0.05 level \\
** Pearson's Correlation is significant at the 0.01 level.
\end{tabular}

\section{DISCUSSION}

Stress in nursing students is an area of growing concern and it may result in psychological distress, physical complaints, behavior problems and poor academic performance. Present study was carried out to assess self esteem level and academic stress among nursing students and factor correlated with academic stress and self esteem.

This study found self esteem level was low and academic stress was high among Nepalese nursing students. Present study found that only $22 \%$ students have high self-esteem and $74 \%$ students have high academic stress. This finding is little bit different with the findings of the study conducted by Ahamad which found that $86 \%$ of the study subjects had 
high or normal self - esteem and $14 \%$ had low self-esteem. ${ }^{11}$

Result of this study shows academic stress and self esteem is inversely correlated. Many other study findings support these findings. ${ }^{12-17}$ But, some study findings show there is not significant relationship between stress and self esteem. ${ }^{18}$

This study found bachelor level students have high self esteem than Certificate level students, in other words higher the education higher the self esteem. This finding is supported by other studies too. ${ }^{19,20}$ In contrast; a study finding shows the majority of PCL nursing students have high level of self-esteem. Difference in self-esteem was insignificant among the first, second and third year PCL nursing students. ${ }^{21}$ But present study does not compares the self esteem among the nursing students of different years.

This study found lower the education higher the academic stress. This finding was supported by past research findings of Wintre and Yaffe. ${ }^{22}$ Contrast to these findings, Elias and colleagues' stated medical students and final-year students were more likely to experience higher levels of stress compared to the other students. ${ }^{23}$ This may happen because the first-year students are able to adapt to the new environment fast during university life transition described by Towbes and Cohen. ${ }^{24}$ This may be due to the higher level of university education which causes more academic stress or their consideration about their job opportunities as they complete the study. ${ }^{24}$ Another study result demonstrated a significant difference occurs between younger and older students on Perceived Stress Scale. Academic stress is higher in younger students than older students as younger students are not that much adjusted to academic stress of university as seniors are. ${ }^{25}$

Finances can be a strain for the students. A study found that financial concerns cause significant stress for graduate students and produce $19 \%$ high levels of stress. ${ }^{26}$ Another study in Malayasia by Aniza Abdul Manaf found that $58.7 \%$ and $43.3 \%$ perceived stress due to financial problem and family conflict respectively. ${ }^{27}$ This study also found that those students supported financially less than Rs 6000/month had significant high stress. This finding is also supported by finding of the study done in India, which shows financial problem as stress factors by $50 \%$ and $60 \%$ by adolescence girls of Hyderabad and Hisar city respectively. ${ }^{28}$ In the same

\section{REFERENCES}

1. Webster' New World Dictionary;1982.

2. Hudd S, Dumlao J, Erdmann-Sager D, Murray D, Phan E, Soukas N, et al. Stress at college: Effects on health habits, heath status, and selfesteem, 2000. Available from: http://www.google.com.np/search?aq $=f \&$ sourceid=chrome $\&$ ie $=U T F-8 \& q=w w$.

3. Sassaroli S, Ruggiero GM. The role of stress in the association between low self esteem, perfectionism, and worry, and eating disorders. International Journal of Eating Disorders. 2005,32,135-41. way, the findings regarding family conflict were $47.5 \%$ from Hisar city and $72.5 \%$ from Hyderabad city. ${ }^{28}$ This study also shows students having high perceived family support have high self esteem and low academic stress.

Despite all the sources of stress in the academic environment, the future of the students depends mostly on high academic performance. It is estimated that 10 to 30 percent of the students experience academic related stress that affects their academic performance. ${ }^{7,8}$ Studies illustrated that self-esteem levels are high in childhood, drops during adolescence, rises gradually throughout adulthood, and declines sharply in elderly. ${ }^{29}$

\section{Limitation of the Study}

Like many other studies, this study is not free from limitations and findings of this study should be interpreted based on these limitations. Firstly, this study is a small crosssectional study carried out in one academic institution and findings of this study cannot be generalized to all the nursing students of Nepal. Secondly, cross-sectional nature of the study may not establish the relationship between dependent and independent variables. Thirdly, cut off point used for low and high academic stress is arbitrary in this study and its findings should be interpreted accordingly. Fourthly, this study does not compare the academic stress and self esteem between different years of students within the same level.

\section{CONCLUSION}

This study found nursing students have high academic stress and low self esteem. Variables significantly related with high academic stress and low self esteem was lower the age, lower the education and low perceived family support. Findings based on this study cannot be generalized and there should be further study to know the real cause of low self esteem and high academic stress among the Nepalese nursing students so that it will help to get the quality nursing education in the coming days.

\section{ACKNOWLEDGEMENT}

Our special thanks to all the participants of the study for their co-operation and other supportive personnel.

4. Chris E, Pais M, Senthil PK, Sisodia V. Perceived self-esteem amongst first-year nursing students - a cross-sectional survey. International Journal of Health and Rehabilitation Sciences. 2012;1(2):74-80.

5. Erikson E. Identity: Youth and Crisis. 1968, New York: w.w. Norton \& Company, Inc.

6. Giarrusso R, Mabry JB, Bengtson VL. The aging self in social contexts. Handbook of aging and the social sciences $\left(5^{\text {th }}\right.$ ed.), Academic Press, San Diego, 2001, pp. 295-312. 
7. Black J, Hawks J, Keene A. Medical Surgical Nursing, Clinical Management for Positive Outcomes, $6^{\text {th }}$ ed. 2008. WB Saunders, US

8. Uday KS, Vibha S, Mahendra KN. Development of a scale for assessing academic stress: a preliminary report. Journal of the Institute of Medicine 2001; 23: $105-112$

9. Rosenberg, M. Society and adolescent self-image. Princeton, NJ: Princeton University Press 1965.

10. Robins RW, Noftle E, Trzesniewski KH, Roberts BW. Do people know how their personality has changed? Correlates of perceived and actual personality change in young adulthood. Journal of Personality 2005,73,481-521.

11. Ahamad NA. Study to investigate relation between self-esteem and moral judgment. Interdisciplinary journal of contemporary research in business 2001; 3(6): 27-33.

12. Joshi Y. P. "Study on Self-esteem Level and Academic Stress of University Students" Central Campus Kirtipur in 2007.

13. Ruth Lo. A longitudinal study of perceived level of stress, coping and self-esteem of undergraduate nursing students: an Australian case study. Journal of Advanced Nursing 2002; 39(2):119-26.

14. Dixit M, Singh N. Academic Stress of School Students in Relation to Their Self-Esteem - Global Journal for Research Analysis 2015 March; 4(3):2277-8160.

15. Wahyu R. Academic stress on college students: the role of self-esteem and psychological well-being. Presented in International Seminar on Global Education II, Universitiy Kebangsaan Malaysia, Bangi, 2012, February, 24-25.

16. Isiklar A. Examining psychological well-being and self-esteem levels of Turkish students in gaining identity against role during conflict period. Journal of Instructional Psychology 2012;39:41-50.

17. Wang DC, Castaneda-Sound C. The role of generational status, self-esteem, academic self-efficacy, and perceived social support in college students' psychological well-being. Journal of College Counseling 2008;11:101-18.

18. POLK AN. Effects of Stress on Self-esteem. National Undergraduate Research Clearinghouse, 2006. Available online at http://www. webclearinghouse.net/volume/. Retrieved June 24, 2015.
19. Edwards D, Burnard P, Bennett K Hebden U. A longitudinal study of stress and self-esteem in student nurses. Nurse Educ Today. 2010 Jan; $30(1): 78-84$.

20. Chaves ECL, Simão TP, Oliveira IS, Souza IP, lunes DH, Nogueira DA. Assessment of nursing students' self-esteem at a university in the South of Minas Gerais (Brazil). Education Information. 2013;31(2): 261-9.

21. Shrestha T. Self-esteem and Stress Coping among Proficiency Certificate Level Nursing Students in Nursing Campuses. J Nepal Health Res Counc 2013 Sep; 11(25):283-8.

22. Winter, M.G., Yaffe M. First-year students' adjustment to university life as a function of relationship with parents. Journal of Adolescent Research 2000, 5(1): 9 -37.

23. Habibah E, Wong S.P., Maria C.A. Stress and Academic Achievement among Undergraduate Students in Universiti Putra Malaysia. Procedia - Social and Behavioral Sciences 201; 29: 646-55.

24. Towbes LC, Cohen, LH. Chronic stress in the lives of college students: Scale development and prospective prediction of distress. Journal of Youth and Adolescence 1996; 25: 199-217.

25. Khan MJ, Seema A, Hafsa K. Effect of Perceived Academic Stress on Students' Performance. FWU Journal of Social Sciences Winter 2013;7(2):146-51.

26. Hudson SA, O'Regan J. Stress and the graduate psychology student. Journal of Clinical Psychology 1994;50:973-7.

27. Anizan B Manaf Abdul. Perceived stress factors among secondary school adolescent in Kaula Pilah district, Malaysia Journal of Adolescent 2009;30: 51-62

28. Dubat S, Punia Y, Rashmi G. A study on Life stress and coping Styles among adolescent girls. Department of Human development and family studies: Journal of Social Science. 2010;14(2):191-4.

29. Robins RW, Trzesniewski KH, Tracy JL, Gosling SD. Global Self-Esteem across the Life Span. Journal of Psychology and Aging 2002;17(3): 423-34. 